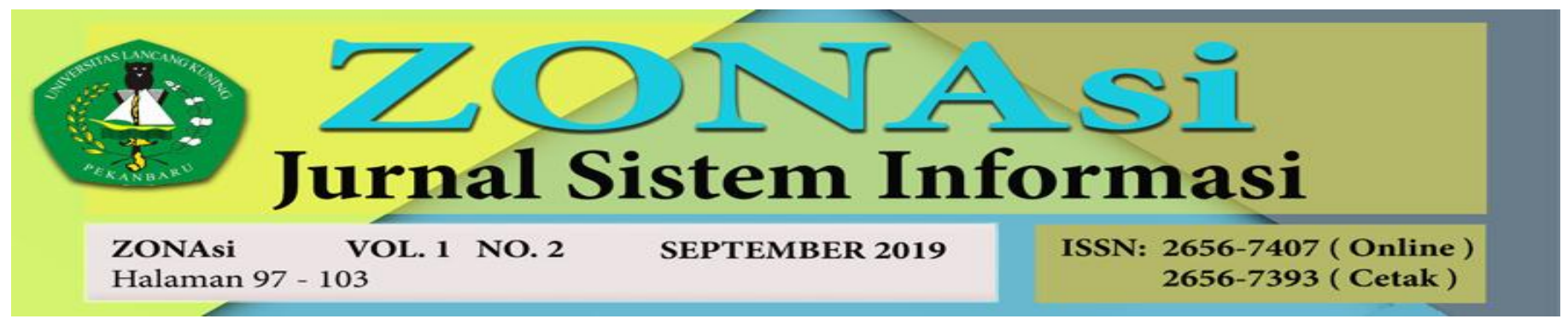

\title{
SPK Pemilihan Presiden Mahasiswa Unilak Dengan Metode Simple Additive Weighting (SAW)
}

\author{
Roki Hardianto ${ }^{1}$ \\ Teknik Informatika, Fasilkom, Universitas Lancang Kuning \\ J1. Yos Sudarso KM. 8 Rumbai, Pekanbaru, Riau, telp. 08117532015 \\ e-mail: roki@unilak.ac.id ${ }^{1}$
}

\begin{abstract}
Abstrak
Penelitian ini adalah tentang system pengambilan keputusan bagaimana presiden mahasiswa di Universitas Lancang Kuning. Metode yang digunakan adalah metode Simple Additive Weighting (SAW). Menggunakan 5 kriteria penilaian dalam proses pengambilan keputuasan. Dari kriteria ini dilakukan proses SPK menggunakan metode SAW melalui beberapa proses normalisasi sehingga benar-benar didapatkan hasil yang bisa menjadi sebuah keputusan. Hasil penelitian ini diharapkan dalam kegiatan proses penilaian calon Presiden Mahaiswa Universitas Lancang Kuning lebih mudah dan cepat serta meningkatkan kinerja Komisi Pemilihan Umum yang dibentuk oleh Universitas menggunakan metode Simple Additive Weighting $(S A W)$.
\end{abstract}

Kata kunci: SPK, SAW, MADM, PRESMA

Abstrak

This research is about the decision making system of how the student president at Lancang Kuning University. The method used is the Simple Additive Weighting (SAW) method. Use 5 assessment criteria in the decision-making process. From this criterion the SPK process uses the SAW method through a number of normalization processes so that the actual results that can be obtained are a decision. The results of this study are expected to be easier and faster in the process of evaluating candidates for the President of the Student Lancang Kuning University and improving the performance of the General Election Commission established by the University using the Simple Additive Weighting (SAW) method.

Keywords : SPK, SAW, MADM, PRESMA

\section{Pendahuluan}

Dalam kehidupan kita sering mendapatkan keputusan dimana keputusan itu dapat menentukan masa depan kita, ketika memilih sebuah keputusan kita mempertimbangkan apakah keputusan tersebut berdampak untung atau tidak. Dalam berbisnis sangat penting untuk menentukan keputusan yang tepat demi kesuksesan dalam berbisnis, tidak hanya dalam berbisnis dalam edukasi, pengadilan, dan perancangan sistem. Kita akan terus di hadapi dengan keputusan.

Multiple Attribute Decision Making (MADM) adalah metode yang digunakan untuk mencari solusi alternatif optimal dari beberapa solusi alternatif dengan kriteria tertentu 
berdasarkan objek yang diteliti. Inti dari MADM adalah menentukan nilai bobot untuk setiap atribut, kemudian dilanjutkan dengan proses perangkingan yang akan menyeleksi alternatif yang sudah diberikan. (Setiaji, 2014)

Simple Additive Weighting adalah metode pengambilan keputusan dengan cara menormalisasi matriks ke suatu sekala yang dapat di petimbangkan, dengan data - data yang sudah di kumpulkan lalu dibuatkan krikteria penilaian berdasarkan data - data tersebut.

Dengan menggunakan metode SAW hasil yang didapatkan akan terlihat jelas, dengan begitu dapat di tentukan dengan optimal siapa yang harus dipilih untuk mengikuti lomba berdasarkan bobot terbesar. Oleh karena itu penggunaan metode dalam memilih keputusan sanggat berguna untuk kehidupan sehari - hari sesuai dengan kondisi masalah tersebut bagusnya menggunakan metode apa agar mencapai hasil yang di ingginkan.

\section{Metode Penelitian}

\section{A. Sistem Pendukung Keputusan.}

Sistem pendukung keputusan adalah sistem informasi berbasis komputer yang interaktif, dengan cara mengolah data dengan berbagai model untuk memecahkan masalah-masalah yang tidak terstruktur sehingga dapat memberikan informasi yang bisa digunakan oleh para pengambil keputusan dalam membuat sebuah keputusan. Dalam sebuah sistem pendukung keputusan, sumber daya intelektual yang dimiliki seseorang dipadukan dengan kemampuan komputer untuk membantu meningkatkan kualitas dari keputusan yang diambil. Pengambilan keputusan merupakan sebuah proses memilih sebuah tindakan diantara beberapa alternatif yang ada, sehingga tujuan yang diinginkan dapat tercapai. (Chamid, 2016).

\section{B. Metode / Permodelan yang Digunakan}

\section{B.1 Simple Additive Weighting (SAW)}

Metode SAW juga merupakan metode MADM yang paling sederhana dan paling banyak digunakan. Metode ini juga metode yang paling mudah untuk diaplikasikan, karena mempunyai algoritma yang tidak terlalu rumit. Metode SAW sering juga dikenal sebagai metode penjumlahan terbobot.

Konsep dasar metode SAW adalah mencari penjumlahan terbobot dari rating kinerja pada setiap alternatif pada semua atribut. Metode SAW membutuhkan proses normalisasi matriks keputusan $(\mathrm{X})$ ke suatu skala yang dapat diperbandingkan dengan semua rating alternatif yang ada. (Setiaji, 2014)

Formula untuk melakukan normalisasi tersebut adalah sebagai berikut:

$$
\boldsymbol{r}_{i j}=\left\{\begin{array}{l}
\frac{\boldsymbol{X}_{i j}}{\boldsymbol{M a x} \boldsymbol{X}_{i j}} \text { jika } j \text { attribut keuntungan (benefit) } \\
\frac{\boldsymbol{M i n} \boldsymbol{X}_{i j}}{\boldsymbol{X}_{i j}} \text { jika } j \text { attribut biaya (cost) }
\end{array}\right.
$$

Keterangan:

$\operatorname{Max} X_{i j}=$ Nilai terbesar dari setiap kriteria i.

Min $X_{i j}=$ Nilai terkecil dari setiap kriteria i.

$X_{i j}=$ Nilai atribut yang dimiliki dari setiap kriteria.

Benefit $=$ Jika nilai terbesar adalah yang terbaik.

Cost $=$ Jika nilai terkecil adalah yang terbaik.

Dimana $\mathrm{r}_{\mathrm{ij}}$ adalah rating kinerja ternormalisasi dari alternatif $A_{i}$ pada atribut $C_{i j} i=1,2, \ldots, n$.

Nilai preferensi untuk setiap alternatif $\left(\mathrm{V}_{\mathrm{i}}\right)$ di berikan sebagai: 
$V_{1}=\sum_{j=1}^{n} W_{j} R_{i j}$

Keterangan:

$\mathrm{V}_{\mathrm{i}}=$ Rangking untuk setiap alternatif.

$\mathrm{W}_{\mathrm{j}}=$ Nilai bobot rangking (dari setiap kriteria).

$\mathrm{r}_{\mathrm{ij}}=$ Nilai rating kinerja ternormalisasi.

Nilai $V_{i}$ yang lebih besar mengidentifikasikan bahwa alternatif $A_{i}$ lebih terpilih.

Metode SAW mengenal adanya 2 (dua) atribut yaitu kriteria keuntungan (benefit) dan kriteria biaya (cost). Perbedaan mendasar dari kedua kriteria ini adalah dalam pemilihan kriteria ketika mengambil keputusan.

Menurut Fishburn dan MacCrimmon dalam (Munthe, 2013) Ada beberapa langkah dalam penyelesaian metode Simple Additive Weight (SAW) adalah sebagai berikut :

1. Menentukan kriteria-kriteria yang dijadikan acuan dalam pendukung keputusan yaitu Ci.

2. Memberikan nilai bobot $(\mathrm{W})$.

3. Menetukan alternatif yang dijadikan kandidat dalam pengambil keputusan.

4. Menentukan rating kecocokan setiap alternatif pada setiap kriteria.

5. Membuat matriks keputusan berdasarkan kriteria (Ci).

6. Kemudian melakukan normalisasi matriks berdasarkan persamaan yang disesuaikan dengan jenis atribut (atribut keuntungan maupun atribut biaya) sehingga diperoleh matriks ternormalisasi R.

7. Hasil akhir diperoleh dari proses perangkingan yaitu penjumlahan dari perkalian matriks ternormalisasi $\mathrm{R}$ dengan vector bobot sehingga diperoleh nilai terbesar yang dipilih sebagai alternatis terbaik (Ai) sebagi solusi.. (Frieyadie, 2016)

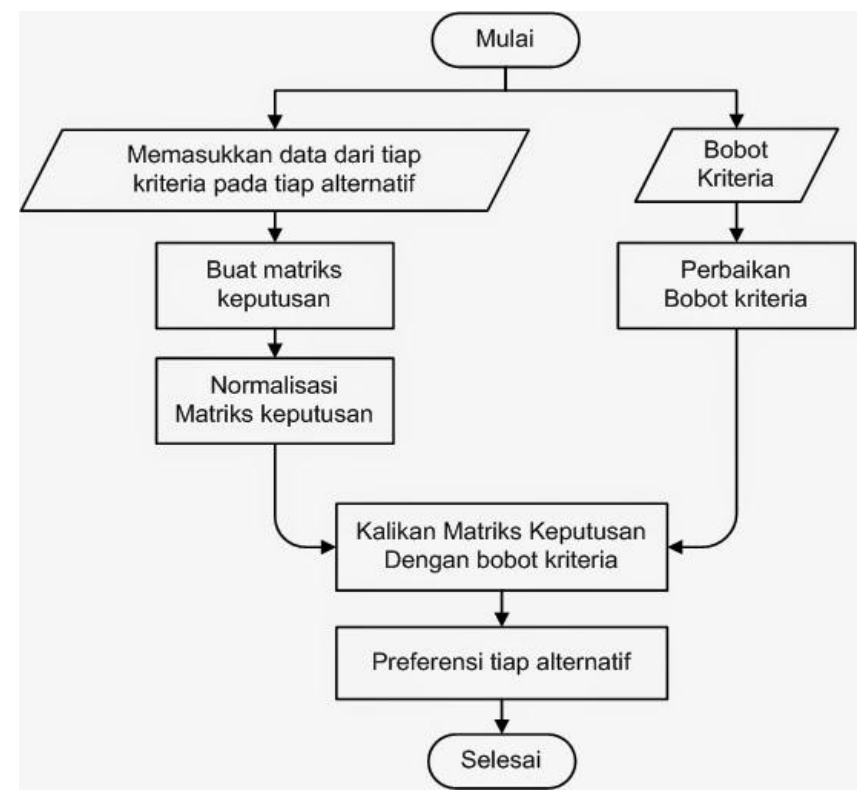

Gambar 2. Flowchart SAW 


\section{Hasil dan Pembahasan}

\section{A. Analisa Pembahasan}

Dalam menentukan kadidat untuk disertakan dalam pemilihan Presiden Mahasiswa (PRESMA) bisa digunakan sistem yang dapat membantu dalam menentukan keputusan yang optimal. Untuk mempermudah dan mempercepat panitia dari UNILAK dalam menentukan calon PRESMA yang sesuai menjadi Presiden Mahasiswa (PRESMA). Untuk mendapatkan calon PRESMA tersebut maka harus di tentukan krikteria-krikterianya terlebih dahulu. Krikteria yang diterapkan dalam studi kasus ini adalah Wawasan Yang Luas, Keaktifan Organisasi, Prestasi, Orasi, Kepribadian. Dalam pemilihan Presiden Mahasiswa (PRESMA) UNILAK dengan menggunakan metode Simple Additive Weighting dibutuhkan krikteria-kerikteria dan bobot agar dapat di perhitungkan, shingga didapatkanya calon peserta yang sesuai. Dalam proses penilaian tersebut digunakan metode Simple Additive Weighting.

\section{A. Analisa Perhitungan SPK metode Simple Additive Weighting (SAW)}

Berikut ini adalah tahapan proses pengambilan keputusan dengan menggunakan metode SAW :

1. Menentukan kriteria - kriteria yang akan dijadikan acuan dalam pengambilan keputusan. Adapun kriteria dalam penelitian ini adalah:

Tabel 1. Kriteria Acuan

\begin{tabular}{cc}
\hline Kode & Kriteria \\
\hline $\mathrm{C} 1$ & Wawasan yang luas \\
\hline $\mathrm{C} 2$ & Keaktifan organisasi \\
\hline C3 & Prestasi \\
\hline C4 & Orasi \\
\hline C5 & Kepribadian \\
\hline
\end{tabular}

2. Memberikan nilai bobot (W).

Diberikan nilai bobot $(\mathrm{W})$ untuk setiap kriteria sebagai berikut:

$\mathrm{C} 1=$ Wawasan yang luas $(30 \%)=0,3$

$\mathrm{C} 2=$ Keaktifan Organisasi $(25 \%)=0,25$

$\mathrm{C} 3=$ Prestasi $(20 \%)=0,2$

$\mathrm{C} 4=$ Orasi $(15 \%)=0,15$

$\mathrm{C} 5=$ Kepribadian $(10 \%)=0,1$

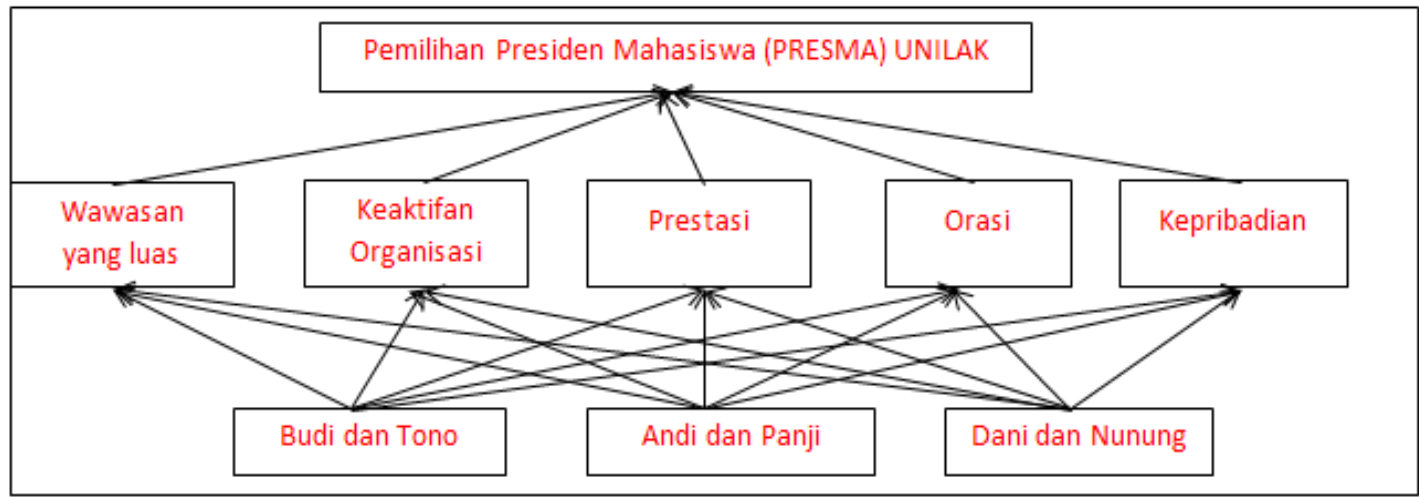

Gambar 2. Hasil olahan dari metode SAW 
3. Menentukan alternatif yang di jadikan kandidat dalam pengambil keputusan.

Ada 3 orang yang menjadi kandidat (alternatif) untuk Pemilihan Presiden Mahasiswa, yaitu:

Tabel 2. Alternatif

\begin{tabular}{cc}
\hline Kode & Alternatif \\
\hline A1 & Budi dan Tono \\
\hline A2 & Andi dan Panji \\
\hline A3 & Dani dan Nanang \\
\hline
\end{tabular}

4. Menentukan Nilai Alternatif Berdasarkan Kriteria

Tabel 3. Nilai Alternatif Berdasarkan Kriteria

\begin{tabular}{l|l|l|l|l|l}
\hline \multirow{2}{*}{ Alternative } & \multicolumn{5}{|c}{ Kriteria } \\
\cline { 2 - 6 } & C1 & C2 & C3 & C4 & C5 \\
\hline A1 & 85 & 65 & 80 & 75 & 70 \\
\hline A2 & 60 & 80 & 75 & 65 & 80 \\
\hline A3 & 70 & 73 & 90 & 55 & 85 \\
\hline
\end{tabular}

5. Membuat matriks keputusan berdasarkan criteria (Ci) :

$$
X=\left\{\begin{array}{lllll}
85 & 65 & 80 & 75 & 70 \\
60 & 80 & 75 & 65 & 80 \\
70 & 73 & 90 & 55 & 85
\end{array}\right\}
$$

6. Menormalisasi matriks X menjadi matriks $\mathrm{R}$

Tabel 4. Penggolongan Kriteria

\begin{tabular}{lcc}
\hline \multicolumn{1}{c}{ Kriteria } & Benefit & Cost \\
\hline Wawasan yang luas & $\checkmark$ \\
\hline Keaktifan Organisasi & $\checkmark$ \\
\hline Prestasi & $\checkmark$ \\
\hline Orasi & $\checkmark$ \\
\hline Kepribadian & $\checkmark$ \\
\hline
\end{tabular}

a. $r_{11}=\frac{85}{\max \{85 ; 60 ; 70\}}=\frac{85}{85}=1$

$$
r_{21}=\frac{60}{\max \{85 ; 60 ; 70\}}=\frac{60}{85}=0,71
$$




$$
\begin{aligned}
& r_{31}=\frac{70}{\max \{85 ; 60 ; 70\}}=\frac{70}{85}=0,82 \\
& \text { b. } \quad r_{12}=\frac{65}{\max \{65 ; 80 ; 73\}}=\frac{65}{80}=0,81 \\
& r_{22}=\frac{80}{\max \{65 ; 80 ; 73\}}=\frac{80}{80}=1
\end{aligned}
$$

Dari hasil diatas maka dapat matrik normalisasi seperti dibawah ini :

$$
R=\left\{\begin{array}{ccccc}
1 & 0,81 & 0,89 & 1 & 0,82 \\
0,71 & 1 & 0,83 & 0,87 & 0,94 \\
0,82 & 0,91 & 1 & 0,73 & 1
\end{array}\right\}
$$

7. Melakukan proses perankingan

Pada proses perangkingan dengan bobot yang didapat dari proses pencarian dengan bobot keputusan $\mathrm{w}=[0,3 ; 0,25 ; 0,2 ; 0,15 ; 0,1]$ maka diperoleh hasil sebagai berikut :

$$
\begin{aligned}
& V_{1}=(0,3)(1)+(0,25)(0,81)+(0,2)(0,89)+(0,15)(1)+(0,1)(0,82)=0,9125 \\
& V_{2}=(0,3)(0,71)+(0,25)(1)+(0,2)(0,83)+(0,15)(0,87)+(0,1)(0,94)=0,8535 \\
& V_{3}=(0,3)(0,82)+(0,25)(0,91)+(0,2)(1)+(0,15)(0,73)+(0,1)(1)=0,8830
\end{aligned}
$$

Terdapat 3 hasil akhir yakni V1, V2 dan V3, dari ketiga keputusan tersebut V1 adalah hasil dengan bobot tertinggi. Maka keputusan didapat adalah V1 atau alternative A1 yaitu pasangan Budi dan Tono.

\section{Kesimpulan}

Dari ouput penelitian Sistem Penunjang Keputusan yang dilakukan dengan menggunakan metode SAW, maka kesimpulannya adalah :

a. Penelitian ini membantu komisi pemilihan presiden mahasiswa dan warga mahasiswa Universitas Lancang Kuning dalam mengambil keputusan hasil pemilihan dan survey kemungkinan calon presiden mahasiswa terpilih pada saat pemilu

b. Dengan menggunakan SPK dapat mempercepat dalam pengambilan keputusan

c. Calon pemilih bisa dengan cerdas dalam memilih Presma

d. Hasil penelitian ini bukan hasil final, hasil final adalah murni perhitungan suara pemilu.

\section{Saran}

Penelitian tentang SPK metode SAW bisa dikembangkan lagi kepada pemilu dengan cakupan yang lebih luas. Seperti pemilihan kepala desa, pemilihan calon legislatif maupun pemilu lainnya. Juga bisa kepada penelitian objek selain pemilu.

\section{Daftar Pustaka}

[1] anggoro, c. t. (2016). sistem pendukung keputusan pemilihan karyawan terbaik mengunakan metode saw. 1-9.

[2] azzam, m. f., laksana, t. g., \& romadlon, f. (n.d.). fuzzy multi-atribute decision making ( fuzzy madm) dengan metode simple additive weighting dalam mahasiswa informatika berbasis web di institut teknologi telkom purwokerto. 1-7. 
[3] chamid, a. a. (2016). prioritas kondisi rumah. jurnal simetris, 7(2), 537-544.

[4] frieyadie. (2016). penerapan metode simpe additive weighting (saw) dalam sistem pendukung keputusan promosi kenaikan jabatan. jurnal pilar nusa mandiri, 11(1), 37-45.

[5] nugraha, f., surarso, b., \& noranita, b. (2016). sistem pendukung keputusan evaluasi pemilihan pemenang pengadaan aset dengan metode simple additive weighting (saw). jurnal sistem informasi bisnis, 2(2), 67-72. https://doi.org/10.21456/vol2iss2pp067-072

[6] setiaji, p. (2014). sistem pendukung keputusan dengan metode simple additive weighting. sistem pendukung keputusan dengan metode simple additive weighting untuk pemilihan kepala cabang, 8, 1-3.

[7] taufiq, r., \& mustofa, i. s. (2017). perancangan sistem pendukung keputusan kejurusan menggunakan metode simple additive weighting (saw) di sma negri 15 tangerang. jurnal ti atma luhur, 4(1), 103-114. retrieved from http://jurnal.atmaluhur.ac.id/index.php/ti_atma_luhur/article/view/273/224 